SILVA, M.C.C.; MEDEIROS, J.F.; NEGREIROS, M.Z.; SOUSA, V.F. Produtividade de frutos do meloeiro sob diferentes níveis de salinidade da água de irrigação, com e sem cobertura do solo. Horticultura Brasileira, Brasília, v.23, n.2, p.202-205, abr-jun 2005.

\title{
Produtividade de frutos do meloeiro sob diferentes níveis de salinidade da água de irrigação, com e sem cobertura do solo ${ }^{1}$
}

\author{
Marcelo Cleón de C. Silva²; José Francismar de Medeiros²; Maria Zuleide de Negreiros²; Valdemício F. de \\ Sousa $^{3}$
}

${ }^{2}$ ESAM, C. Postal 137, 59600-000 Mossoró-RN; E-mail: mdecastro70@ @otmail.com; jfmedeir@esam.br; ${ }^{3}$ Embrapa Meio-Norte, C. Postal 01, 64006-220 Teresina-PI; E-mail: vfsousa@cpamn.embrapa.br

\section{RESUMO}

No presente estudo avaliou-se o número e a produtividade de frutos de dois híbridos de meloeiro submetidos a diferentes níveis salinos da água de irrigação e cobertura do solo. Utilizou-se um esquema fatorial $3 \times 2 \times 2$ em blocos completos casualizados com quatro repetições. Os fatores foram três níveis de salinidade da água de irrigação, com condutividade elétrica de $1,2 \mathrm{dSm}^{-1} ; 2,5 \mathrm{dSm}^{-1} \mathrm{e}$ 4,4 $\mathrm{dSm}^{-1}$ respectivamente, dois híbridos, Gold Mine e Trusty, com e sem cobertura de solo por filme de polietileno dupla face pretoprateado. Apenas o híbrido Trusty apresentou redução do número de frutos total em resposta à salinidade da água de irrigação. A produtividade de frutos comerciáveis foi semelhante em ambos os híbridos, reduzindo-se com o aumento da condutividade elétrica. Para a cobertura do solo, os dois híbridos também reagiram de forma diferenciada, com número de frutos total e produtividade mais elevados no híbrido Trusty com solo coberto.

Palavras-chave: Cucumis melo L., plasticultura, salinidade.

\section{ABSTRACT}

Fruit Yield of muskmelon plants grown at different levels of salinity of irrigation water, with and without soil covering

The number and the yield of fruits from two hybrid of muskmelon, submitted to different saline levels of irrigation water and soil covering was evaluated. A factorial outline was used $3 \times 2 \times$ 2 in a complete randomized blocks design with four replications. The factors were three levels of salinity of irrigation water, with electric conductivity of $1.2 \mathrm{dSm}^{-1} ; 2.5 \mathrm{dSm}^{-1}$ and $4.4 \mathrm{dSm}^{-1}$ respectively, two hybrids, Gold Mine and Trusty, with and without soil covering using black-silvery double face polyethylene film. The hybrids reacted in different ways to the salinity of irrigation water. Reduction on the total number of fruits was observed only in the hybrid Trusty. The marketable yield of fruits was similar in both hybrids, being reduced with the increase of the electric conductivity. For the usage of soil covering the hybrids also reacted in a different way. The hybrid Trusty produced greater number of fruits and higher yield in treatments using soil covering.

Keywords: Cucumis melo L., plasticulture, salinity.

\section{(Recebido para publicação em 3 de janeiro de 2004 e aceito em 1 de março de 2005)}

\begin{abstract}
$\mathrm{A}$ cultura do meloeiro é de grande importância sócio-econômica para o Brasil, promovendo empregos e renda para o homem do campo, com a geração em torno de 20.000 a 30.000 empregos diretos no Nordeste brasileiro (PEDROSA, 1997). Nesta região, essa cucurbitácea vem se destacando como a principal olerícola cultivada, sendo responsável por mais de $93 \%$ da produção brasileira (MAA, 2001). O Rio Grande do Norte é atualmente o maior produtor, com uma área de 4.740 ha (IDEMA, 1999).
\end{abstract}

No cultivo do meloeiro é de grande importância a produção de frutos de boa qualidade, visto que parte da produção é exportada para a Holanda, Inglaterra e Finlândia (AGRIANUAL, 2000). Para obter frutos de alta qualidade é necessário utilizar tecnologias apropriadas, entre elas, a cobertura do solo com filme plástico, que oferece vantagens como menor incidência de ervas daninhas e maior economia da água de irrigação (COSTA GARCIA, 1985). Araújo (2000) comparou, entre vários métodos de cobertura, o filme de polietileno dupla face prateado e o solo descoberto, observando que essa cobertura não apresentou diferença significativa para número, peso médio e produtividade de frutos comerciáveis do híbrido Gold Mine. Ferreira (2001) comparou a cobertura do solo com palha de carnaúba, filme de polietileno preto, filme de polietileno dupla face prateado e solo descoberto. Verificou que o meloeiro Gold Mine cultivado em solo descoberto produziu maior percentagem de frutos tipo exportação e que a cobertura com filme de polietileno preto propor- cionou maior número de frutos comerciáveis.

Na região oeste do Rio Grande do Norte, a água utilizada para a cultura do meloeiro provém de poços rasos (Calcário-Jandaíra), sendo considerada de baixa qualidade por apresentar salinidade média de $2,5 \mathrm{dSm}^{-1}$ (LISBOA, 2002). Na Califórnia, Shannon e François (1978) estudaram a tolerância dos híbridos de melão cantaloupe PMR45, Top Mark e Hale's Best à salinidade e concluíram que a produtividade e o peso médio de frutos decresceram com o aumento da salinidade da água. Em Israel, pesquisa sobre o efeito dos níveis de salinidade da água de 1,2; 7,5 e 14,0 dSm${ }^{-1}$ em 20 híbridos de meloeiro indicaram que 19 deles foram sensíveis à condutividade elétrica $(\mathrm{CE})$ de $14,0 \mathrm{dSm}^{-1}$, havendo decréscimo no peso

${ }^{1}$ Parte da Dissertação de Mestrado em Agronomia do primeiro autor, área de concentração Fitotecnia, pela Escola Superior de Agricultura de Mossoró (ESAM). 
médio de frutos. O híbrido Evan Key, foi o único tolerante à $\mathrm{CE}$ de $14,0 \mathrm{dSm}^{-1}$. A concentração salina não afetou o número de frutos, porém reduziu o peso médio de frutos (MENDLINGER; PASTERNAK, 1992). Em trabalho posterior, Mendlinger (1994) observou decréscimo no peso médio e na produtividade total de frutos de meloeiro tipo Gália com o aumento da salinidade até $8,0 \mathrm{dSm}^{-1}$. Os resultados de Brito (1997) indicaram que níveis de salinidade de até $4,5 \mathrm{dSm}^{-1}$ não reduzem a produtividade de frutos do melão amarelo. Entretanto, Costa (1999) cultivando melão amarelo Gold Mine com águas de salinidade entre $0,55 \mathrm{dSm}^{-1}$ e 2,65 $\mathrm{dSm}^{-1}$ em dois ciclos consecutivos, verificou que a água com $2,65 \mathrm{dSm}^{-1}$ reduziu a produtividade em 10 e $27,5 \%$ no primeiro e no segundo ciclo, respectivamente. O número de frutos por planta foi afetado pela salinidade da água somente no segundo ciclo, com uma redução de $10 \%$. O peso médio de frutos decresceu em 6,0 e 11,3\% no primeiro e segundo ciclos, respectivamente, em decorrência do aumento da salinidade.

O presente trabalho teve como objetivo avaliar o número e a produtividade de frutos de dois híbridos de meloeiro submetidos a três níveis salinos da água de irrigação, com e sem cobertura do solo.

\section{MATERIAL E MÉTODOS}

$\mathrm{O}$ experimento foi realizado de dezembro/2000 a fevereiro/2001 na Fazenda São João Ltda, município de Mossoró (RN).

A classificação climática do local, segundo Koeppen, é do tipo BSwh', sendo a temperatura média de $27,4^{\circ} \mathrm{C}$, a precipitação pluviométrica média de $673,9 \mathrm{~mm}$ e a umidade relativa média de 68,9\% (CARMO FILHO et al.,1991). O solo foi classificado como sendo um Luvissolo Crômico.

As águas de irrigação utilizadas no experimento foram provenientes de poços do Arenito-Açú e do CalcárioJandaíra, apresentando condutividades de $1,2 \mathrm{dSm}^{-1}$ e $2,5 \mathrm{dSm}^{-1}$, respectivamente. O maior nível de salinidade com condutividade elétrica igual a 4,4 dSm${ }^{1}$ foi obtido pela mistura de $1 \mathrm{~g}$ de cloreto de sódio para cada litro da água calcária.

Utilizou-se o delineamento experimental em blocos casualizados completos, em esquema fatorial $3 \times 2 \times 2$, com quatro repetições. Os tratamentos consistiram da combinação de três níveis de salinidade da água de irrigação, 1,2 $\mathrm{dSm}^{-1} ; 2,5 \mathrm{dSm}^{-1}$ e $4,4 \mathrm{dSm}^{-1}$, dois híbridos, Gold Mine e Trusty, em solo descoberto e coberto com filme plástico dupla face de coloração preto e prateada, com $25 \mu \mathrm{m}$ de espessura.

O preparo do solo consistiu de uma escarificação, duas gradagens e uma passagem da enxada rotativa modificada para o preparo dos canteiros. A adubação foi realizada de acordo com a análise do solo, adicionando-se $36 \mathrm{kgha}$ ${ }^{1}$ de N, 12,6 kgha-1 de $\mathrm{P}_{2} \mathrm{O}_{5}$ e $107 \mathrm{kgha}^{-1}$ de $\mathrm{K}_{2} \mathrm{O}$ parceladas diariamente via fertirrigação, na forma de ácido nítrico, nitrato de amônio, monoamônio fosfato, uréia, ácido fosfórico, sulfato de potássio e cloreto de potássio.

Após instalado o sistema de irrigação por gotejamento, foi colocado o filme de polietileno dupla face nas parcelas com cobertura de solo. Utilizou-se o plantio direto, com duas plantas por gotejador espaçadas de $0,15 \mathrm{~m}$. Os gotejadores foram espaçados de $0,5 \mathrm{~m}$ na fileira e 2,0 m entre fileiras. A densidade de plantas foi de 20.000 por ha.

As características avaliadas foram o número de frutos total e comerciáveis, o peso médio de frutos comerciáveis $(\mathrm{kg}) \mathrm{e}$ a produtividade total e comerciável $\left(\mathrm{t} \mathrm{ha}^{-1}\right)$. Conforme padrões da EMBRAPA (2000) foram classificados como frutos comerciáveis do híbrido Gold Mine aqueles de forma elíptica, casca amarela ausente de cicatrizes, polpa branco creme e sem aroma e do híbrido Trusty aqueles de forma esférica, casca reticulada ausente de cicatrizes, polpa salmão e com forte aroma.

Os dados referentes à cobertura do solo para ambos os híbridos foram submetidos à análise de variância, sendo as significâncias testadas em nível de probabilidade de $5 \%$ através do teste " $t$ ". Aqueles referentes à salinidade foram submetidos à análise de regressão. Em algumas características onde não ocorreu interação significativa entre os híbridos utilizou-se o confundimento dos dados (Figuras 1B e 1D).

\section{RESULTADOS E DISCUSSÃO}

O número de frutos total no híbrido Trusty decresceu linearmente, obtendo diferenças percentuais de $13 \%$ e $26 \%$ nas salinidades de $2,5 \mathrm{dSm}^{-1}$ e 4,4 $\mathrm{dSm}^{-1}$, respectivamente, quando comparados com a condutividade elétrica de 1,2 $\mathrm{dSm}^{-1}$ (Figura 1A). Para o híbrido Gold Mine o número de frutos total, não apresentou relação com o aumento da salinidade na água de irrigação. Estes resultados estão de acordo com os observados por Mendlinger e Pasternak (1992) em Israel, com os híbridos Galia, BG3 e BG5, testando níveis de condutividade elétrica entre $1,2 \mathrm{dSm}^{-1} \mathrm{e}$ $14,0 \mathrm{dSm}^{-1}$.

O número de frutos comerciáveis e o peso médio $(\mathrm{kg})$ de ambos os híbridos foram reduzidos $23 \%$ e $25 \%$, respectivamente, com o aumento da salinidade até $4,4 \mathrm{dSm}^{-1}$ (Figura 1B), confirmando Costa (1999), que obteve no híbrido Gold Mine reduções no número de frutos comerciáveis e peso médio de frutos com níveis de $\mathrm{CE}$ de $0,55 \mathrm{dSm}^{-1} \mathrm{e}$ $2,65 \mathrm{dSm}^{-1}$. O peso médio máximo foi obtido com a água de menor salinidade.

A produtividade total sofreu redução em ambos os híbridos com o aumento do nível de salinidade da água (Figura 1C). Resultados semelhantes foram encontrados por Brito (1997), trabalhando com os níveis de salinidade da água de irrigação de $1,50 \mathrm{dSm}^{-1} ; 3,00 \mathrm{dSm}^{-1}$ e 4,50 $\mathrm{dSm}^{-1}$, o qual mostrou que salinidade acima de 4,50 $\mathrm{dSm}^{-1}$ ocasiona uma queda significativa na produtividade do meloeiro. O meloeiro Trusty apresentou maior produtividade total média de 33,91 t ha ${ }^{-1}$, quando comparado ao híbrido Gold Mine que alcançou produtividade total média de 30,09 $\mathrm{t} \mathrm{ha}^{-1}$, diferença esta significativa em nível de $5 \%$ de probabilidade através do teste ' $\mathrm{t}$ '.

$\mathrm{Na}$ produtividade de frutos comerciáveis dos híbridos observou-se declínio na produtividade quando se aumentou os níveis salinos, reduzindo em $15 \%$ e $36 \%$, nas CE de $2,5 \mathrm{dSm}^{-1}$ e $4,4 \mathrm{dSm}^{-1}$, respectivamente, quando comparadas com a salinidade de 1,2 $\mathrm{dSm}^{-1}$ (Figura 1D). A produtividade foi superior na menor concentração de sais na água de irrigação. 

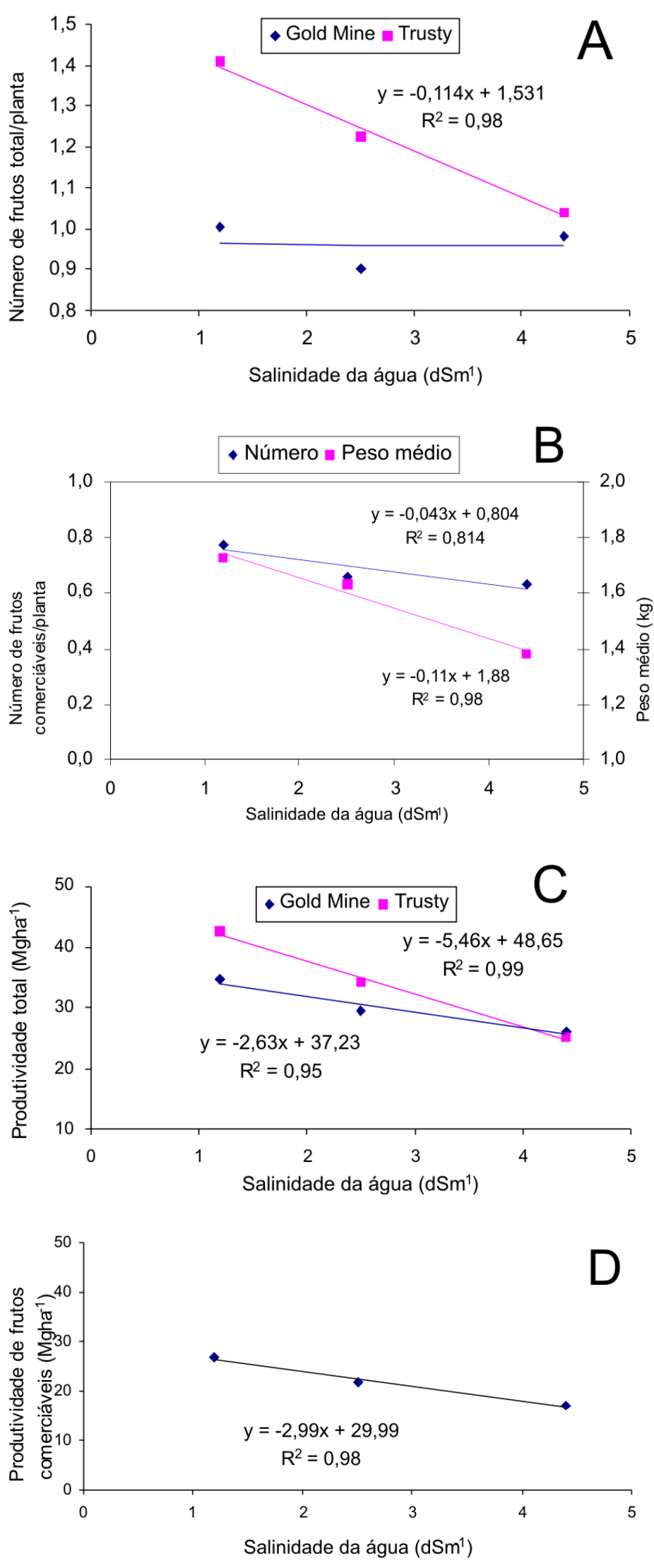

Figura 1. Número de frutos total/planta (A), número de frutos comerciáveis/planta e peso médio (B), produtividade total $\left(\mathrm{Mgha}^{-1}\right)(\mathrm{C})$ e produtividade de frutos comerciáveis $\left(\mathrm{Mgha}^{-1}\right)$ (D) em função dos níveis de salinidade da água de irrigação. ESAM, Mossoró-RN, 2001.
O número de frutos total por planta no híbrido Gold Mine não foi influenciado pela cobertura do solo (Figura 2A). No meloeiro Trusty evidenciou-se diferença significativa ao nível de $5 \%$ de probabilidade, superando o Gold Mine, em ambos os tratamentos. Resultados semelhantes foram observados por Ferreira (2001), com o Gold Mine, o qual não encontrou diferenças entre solo descoberto e coberto com filmes de polietileno preto e dupla-face preto e prateado. Entretanto, para o Trusty evidenciou-se um decréscimo de $16 \%$ no número de frutos quando utilizou-se o solo desnudo.

O número de frutos comerciáveis no híbrido Gold Mine referente à cobertura com filme dupla face não apresentou diferença significativa ao nível de 5\% de probabilidade (Figura 2B). Porém, houve diferença significativa para o híbrido Trusty. O Gold Mine produziu maior número de frutos comerciáveis do que o Trusty, independentemente do tipo de cobertura do solo. Resultados similares foram obtidos por Araújo (2000), que avaliou os efeitos das coberturas do solo com polietileno preto, polietileno dupla face (preto/prateado), e palha de carnaúba sobre o híbrido Gold Mine, não tendo observado diferenças significativas entre os tratamentos para essa característica.

Evidencia-se nas Figuras 2C e 2D, que a produtividade total e comerciável no solo coberto foi superior ao solo descoberto, independente dos híbridos. Para a produtividade total o melão Trusty sobressaiu-se quando foi cultivado com solo coberto. Porém a produtividade total comerciável do híbrido Gold Mine foi superior quando cultivado com cobertura do solo.

Os dois híbridos reagiram de forma diferente à salinidade da água de irrigação, com redução do número total de frutos somente no híbrido Trusty. Porém a produtividade de frutos comerciáveis foi semelhante em ambos os híbridos, reduzindo-se com o aumento da condutividade elétrica. Para a cobertura do solo, os dois híbridos também reagiram de forma diferenciada, com número total de frutos e produtividade mais elevados obtidos no híbrido Trusty com solo coberto. 


\section{AGRADECIMENTOS}

À Fazenda São João Ltda. pelo fornecimento de toda estrutura material e suporte técnico necessário e indispensável à execução do experimento.

\section{LITERATURA CITADA}

AGRIANUAL - Anuário da Agricultura Brasileira - São Paulo-SP: Comunicação, 2000, 546 p. ARAÚJO, A.P. Cobertura do solo e métodos de plantio no cultivo do melão amarelo. $2000.49 \mathrm{f}$. (Tese mestrado) - ESAM, Mossoró.

BRITO, G.N.S. Produtividade do melão irrigado por gotejamento com água de diferentes níveis salinos. 1997. 87 f. (Tese mestrado) - UFC, Fortaleza.

CARMO FILHO, F.; ESPÍNOLA SOBRINHO, J.; MAIA NETO, J.M. Dados meteorológicos de Mossoró (janeiro de 1989 a dezembro de 1990). ESAM, Fundação Guimarães Duque, 1991. 110 p. (Coleção Mossoroense, Série C, 630).

COSTA, M.C. Efeitos de diferentes lâminas de água com dois níveis de salinidade na cultura do meloeiro. 1999. 115 f. (Tese doutorado) - UNESP, Botucatu.

COSTA GARCIA, J. El cultivo del pimiento para pimenton. In: IV Curso Internacional de Horticultura Intensiva. Múrcia, 1985. 31 p.

Embrapa Agroindústria Tropical. Ministério da Agricultura. Melão pós-colheita. Embrapa Comunicação para Transferência de Tecnologia. Série Frutas do Brasil, 10. Brasília-DF. 2000.

FERREIRA, R.L.F. Produção e qualidade de melão cultivado sob condições climáticas resultante de diferentes cobertura do solo e métodos de plantio. 2001. 63 f. (Tese mestrado) - ESAM, Mossoró.

IDEMA, Instituto de desenvolvimento econômico e meio ambiente do Rio Grande do Norte Anuário Estatístico do Rio Grande do Norte. Natal (RN), v.26, p.1-264, 1999.

LISBOA, R.A. Caracterização físico-química e hidrodinâmica das águas subterrâneas usadas para irrigação na área produtora de melão da Chapada do Apodi-RN. 2002. 31 f. (Monografia graduação) - ESAM, Mossoró.

MENDLINGER, S. Effect of increasing plant density and salinity on yield and fruit quality in muskmelon. Scientia Horticulturae, v.57, p.41-49, 1994.

MENDLINGER, S.; PASTERNAK, D. Screening for salt tolerance in melons. HortScience, v.27, n.8, p.905-907, 1992.

MAA - Ministério da Agricultura e do Abastecimento. Mapeamento da fruticultura brasileira. Disponível em:<http://www.agricultura.gov.br/ fruticultura/index.html>. Acesso em Set. 2001. PEDROSA, J.F. Cultura do melão. 4 ed. Mossoró: ESAM, 1997, $51 \mathrm{p}$.

SHANNON, M.C.; FRANÇOIS, L.E. Salt tolerance of three muskmelon cultivars. Journal of the American Society of Horticultural Science, v.103, n.1, p.127-130, 1978.
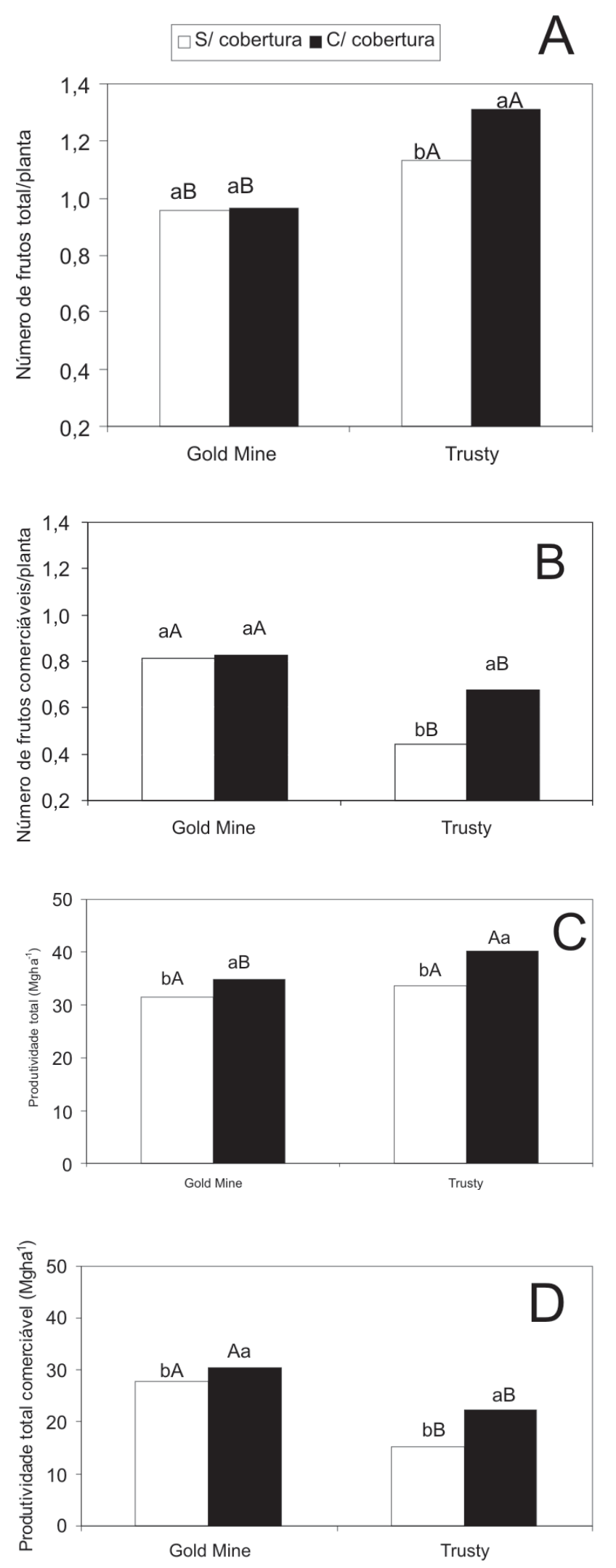

Figura 2. Número de frutos total/planta (A), número de frutos comerciáveis/planta (B), produtividade total $\left(\mathrm{Mgha}^{-1}\right)(\mathrm{C})$ e produtividade total comerciável $\left(\mathrm{Mgha}^{-1}\right)$ (D) dos híbridos Gold Mine e Trusty na ausência e presença de cobertura do solo. ESAM, Mossoró-RN, 2001. *Letras minúsculas comparam cobertura dentro de cada híbrido e as maiúsculas comparam híbridos dentro de cada cobertura. 